\title{
CONDICIONALISMO SÓCIO-CULTURAL DAS ORIGENS DO MOVIMENTO UNIVERSITÁRIO EUROPEU: A SINGULARIDADE DO CASO PORTUGUES (IX).
}

(Conclusão) .

\section{ALDO JANOTTI}

do Departamento de História da Faculdade de Filosofia, Letras e Ciências Humanas da Universidade de São Paulo.

Instalando-se, num ambiente social e culturalmente anacrônico, não conheceu a Universidade portuguêsa aquelas condições básicas renascimento urbano e renascimento cultural do século XII - que presidiram, não apenas, a fundação, mas também o comportamento das Universidades medievais da Cristandade ocidental. Da ausência das referidas condições ressentiram-se, tanto a Universidade, quanto a própria cultura portuguêsa .

Insignificante, senão mesmo nulo, foi o papel desempenhado pela Universidade portuguêsa, na Idade Média. Numa época em que muitảs das Universidades se destacavam e adquiriam fama pela importante influência que exerciam, quer na vida política - nacional e internacional -, quer na vida cultural da Cristandade, Portugal apresentava uma instituição universitária que quase não chegava a dar demonstrações da sua real existência histórica. Não que tenhamos a pretensão de exigir que a Universidade portuguêsa tivesse um comportamento que a elevasse à altura de algumas das grandes Universidade medievais européias: Paris, Bolonha, Oxford, Montpellier, para citar, apenas, quatro exemplos, embora os mais significativos. A Universidade de Paris, segundo Rashdall, tornou-se um grande órgão da opinião pública - e numa época em que o público tinha poucos órgãos de opinião - que se fazia sentir tanto, nas questões internas da França, 
quanto na política eclesiástica da Europa, nela, muito mais do que em Roma, é que era concebida a Teologia da Igreja ocidental (The $M e-$ dieval Universities (1), e, finalmente, natabilizou-se, como o centro da Filosofia escolástica. A Universidade de Bolonha foi, no campo do Direito, aquilo que era a Universidade de Paris, no campo da Filosofia e da Teologia, isto é, a mais alta expressão da atividade jurídica do Ocidente (2) e, em Medicina, deixava-se suplantar apenas pela Universidade de Salerno (3), exercendo ainda grande influência na política italiana e na política internacional. A Universidade de Oxford, cujo rápido desenvolvimento foi uma consequiência da migração em 1167 de professôres e estudantes parisienses para a Inglaterra, ocupou posição destacada na história do pensamento medieval, pois era superada, apenas, por Paris, como foco da Filosofia escolástica (4). E, finalmente, na Universidade de Montpellier, se deu a formação da Medicina acadêmica (5). Não se poderia exigir da Universidade portuguêsa aquilo que estaria reservado apenas às Universidades surgidas, nos grandes centros da cultura européia. Mas que ela tivesse um "comportamento português", ou seja, exercesse uma influência de caráter nacional, pequena que fôsse, justificando assim a sua fundação, nunca seria exigir de mais e sim de menos. Ou nem isto se poderia exigir de uma Universidade, peculiarmente, nascida da ausência de um condicionalismo sócio-cultural?

No campo político não chegamos a pressentir a sua influência . Contràriamente à Universidade de Paris em que, afirma Rashdall (6), mencionar tôdas as ocasiões da sua participação, na política francesa; envolveria uma longa revisão da história da França, especialmente, durante os séculos XIV e XV, mencionar, uma vez sequer, a participação da Universidade coimbrã, na vida política portuguêsa da Idade Média, afigura-se uma verdadeira temeridade. Eis porque, certos autores portuguêses, prudentemente, conjecturam, mas apenas conjecturam, que a Universidade talvez tivesse auxiliado o Mestre de Aviz, na defesa da independência nacional e na conquista do poder real. Tal atitude de prudente conjectura, porém, não encontra confirmação, em documentos comprobatórios da participação da Universidade, nos magnos acontecimentos de 1383-1385. E não devemos nos esquecer, também, de que o famoso João das Regras, o legista da revolução e

\footnotetext{
(1). - In "Cambridge Medieval History, v. VI, p. 598.

(2). - Irsay, op. cit., v. I, p. 75.

(3). - Rashdall, op. cit., loc. cit., p. 560.

(4). - Rashdall, The Universities of Europe in "the Middle Ages", v. III, p. 238 .

(5). - Irsay, op. cit., v. I, p. 120.

(6). - The Medieval Universities, loc. cit., p. 598.
} 
do reinado de D. João I, não foi um produto da Universidade portuguêsa, e sim, da de Bolonha, onde sofrera a influência dos novos glossadores escolásticos, principalmente, de Bártolo Sassoferrato e seus discípulos...

Mas não pressentimos, também, a influência da Universidade, no campo da cultura. Começa que ela padecia de algumas e graves insuficiências, como instituição pedagógica: diminuto era o número dos professôres - como, aliás, diminuto, também, era o número das cadeirás lecionadas --: 1 para cada cadeira, em 1309 (portanto cinco), 14, em 1400, 16, em 1418; números insignificantes, se comparados com os das grandes Universidades estrangeiras; nenhum dêles adquiriu prestígio quanto à sua competência e significativo é o fato de $D$. Fernando ter sido obrigado a importar professôres estrangeiros; pequenas eram as rendas da Universidade: D. Afonso V, em carta dirigida ao papa Xisto IV, atribuia a falta de professôres competentes à exiguidade das referidas rendas; muito limitado era também o número dos seus funcionários, pois só aparecem mencionados os reitores, os conselheiros, os conservadores, o bedel, o procurador, os almotacéis e, a partir de 1310, os procuradores na côrte; corporação de estudantes estrangeiros não possuia; sôbre a existência de uma possível biblioteca universitária não há vestígios; não é matéria pacífica, entre os autores, de que ela gozasse, realmente, do privilégio do jus ubique docendi, até 1380 , não sendo mesmo despropositado acreditar-se que, anteriormente àquela data, a Universidade portuguêsa não tivesse, ainda, alcançado a categoria de Studium generale e que os graus que ela conferia fôssem de pouca validade; e estatutos completos só tardiamente os possuiu (1503).

Além disso, a Universidade portuguêsa "mudou o seu local de habitação, mais frequientemente do que qualquer outra Universidade do mundo" (7) e,

\footnotetext{
"precisamente por causa das suas frequentes mudanças de sede" é que ela "ocupa um lugar completamente à parte na história das Universidades da Idade-Média" (8).
}

Realmente, de tôdas as Universidades, a portuguêsa foi a que mais "migrou": de 1290 a 1308 estêve em Lisboa; transferida em 1308, permaneceu em Coimbra até 1338; voltou a Lisboa de 1338 a 1354; novamente, em Coimbra de 1354 a 1377; novamente em LisII, p. 109

(7)." - Rashdall, The Universities of Europe in "the Middle Ages, v. (8). - Denifle, op. cit., p. 4. 
boa de 1377 a 1537; e, definitivamente, em Coimbra, a partir de 1537. Essas contínuas deslocações são, antes de mais nada, um indício da própria fraqueza cultural da Universidade, pois elas nunca estiveram relacionadas com um problema de caráter pedagógico ou com algum motivo de ordem intelectual ou, ainda, de defesa de privilégios; não deram origem a nenhuma outra Universidade, contràriamente ao que aconteceu na Europa, onde metade das suas Universidades surgiram, como consequiência de tais migrações; diferentemente das migracões das demais Universidades, elas não foram atos da livre vontade de mestres e alunos, e sim, da iniciativa dos monarcas. Interessam-nos, pelc seu significado, três das referidas deslocações: a segunda de 1338, a penúltima de 1377 e a última de 1537. Em 1338 o monarca Afonso IV transferia a Universidade de Coimbra para Lisboa, apresentando, como fundamento

$$
\begin{aligned}
& \text { "a assistência que nesta cidade fazia El-rei a maior parte } \\
& \text { do ano" (9). }
\end{aligned}
$$

A se dar crédito a esta justificativa do monarca, chega-se à conclusão que os reis de Portugal consideravam a Universidade

$$
\begin{aligned}
& \text { "um órgão do Estado e um anexo da côrte - concep̧̧ão } \\
& \text { que é única na história das universidades medievais" (10). }
\end{aligned}
$$

Em 1377, estando outra vez em Coimbra, a Universidade era transferida por D. Fernando para Lisboa, esperando que com esta mudança florescessem mais as ciências em seu país, porque

"alguns lentes que de outros reinos mandamos vir não querem ler, senão na cidade de Lisboa" (11) .

Não queriam os professôres estrangeiros lecionar em Coimbra, cidade pequena e de modestos recursos. Essa recusa é bem uma prova de que a Europa não compreendia a Universidade dissociada da cidade, da verdadeira cidade. Em 1537, porém, a Universidade abandonava Lisboa, indubitàvelmente um grande centro urbano, para se transferir, e definitivamente, para Coimbra,

(9). - Tôrre do Tombo, Chancelaria de D. Afonso IV, 1. IV, fl . 30, apud Teófilo Braga, op. cit., v. I, p. 111.

(10). - Saraiva, op. cit., v. I, p. 107.

(11). - Livro Verde, p. 77. 
"pequenina e adormecida terra de província" (12).

e que não estava, como aliás nunca esteve, em condições de abrigar uma autêntica Universidade. A maioria dos autores portuguêses, inexplicàvelmente, têm procurado contrapor Coimbra a Lisboa, achando que aquela estava mais adequada do que esta para ser a sede da Universidade. Um dêles, entre tantos, Antônio Vasconcelos (13) assim se pronuncia, referindo-se às razões que levaram $D$. Denis a escolher Coimbra, quando mudou a Universidade de Lisboa em 1308:

"A Universidade nã̉o dera em Lisboa os resultados que $D$. Denis esperava. Cidade de muito movimento, com um tráfego comercial já então notavel, frequentada de numerosos negociantes e visitantes estrangeiros e nacionais, atraidos à capital portuguêsa por interesses vários, não era, positivamente, o meio pacato e tranquilo, adequado à meditação e estudo, requerido para uma intensa vida literária e científica. A rapaziada distraia-se muito e estudava pouco, por isso o aproveitamento não podia ser grande";

e referindo-se à Coimbra:

"Pequena, de vida tranquila e pouco movimentada, esta cidade não continha no seio, como Lisboa, elementos perturbadores, que arrancassem os estudantes às suas lucubrações escolares".

Estreita e ao mesmo tempo pitoresca maneira de encarar os fatos históricos, especialmente os da Idade Média, em que a vantagem é tomada por desvantagem, o benefício por malefício. Na realidade, o que houve, concernente às duas últimas transferências da Universidade, foi o choque de duas mentalidades antagônicas, a européia pròpriamente dita e a portuguêsa. Uma urbana, outra rural. Venceu a mentalidade portuguêsa, expressão de um arcáico agrarismo, e a Universidade acabou se transferindo para Coimbra.

Não foi ainda a Universidade um foco assinalável de cultura pois, além da côrte - referimo-nos à época de transição para a Idade Moderna - o único foco de cultura importante continuava a ser o mosteiro de Alcobaça, logo seguido pelo de Santa Cruz de Coimbra. E uma série de fatos revela-nos que ela teve uma história intelectualmente apagada como a indicar, enfàticamente, que a instituição universitária não encontrou em Portugal condições para o seu desenvol-

(12). - Brandão e Lopes de Almeida, op. cit., p. 174.

(13). - Escritos Vários, v. I, p. 79-82. 
vimento. Quase tudo se ignora da atividade intelectual da Universidade e o pouco que se sabe são mais hipóteses, baseadas no que se conhece das Universidades estrangeiras; sôbre os métodos de ensino e os livros adotados, resultado da inexistência de documentação, nada se sabe de positivo; nunca desenvolveu ela uma grande - e nem mesmo "pequena" - doutrina filosófica, a exemplo do que aconteceu com outras Universidades; nunca professôres ou alunos realizaram um movimento - greve, querela com o papado ou com a realeza - em função de qualquer motivo de ordem intelectual. Sempre se ressentiu do fato de ter sido instituida num ambiente, culturalmente anacrônico, não acompanhando a evolução pedagógica e intelectual das suas congêneres européias: em pleno século XV

"permanece fiel à primitiva estrutura universitária do século XIII", tornando-se assim "arcaica, em relação a algumas das grandes universidades européias contemporâneas", onde "grande parte da atividade docente havia sido transferida para os colégios" (14).

e o que se ensinava nela, nos séculos XIV e XV, já no século XII era ensinado em Paris. Uma reforma foi planejada, visando a atualização da Universidade: o culto e viajado infante D. Pedro escrevia de Bruges em 1427 ao monarca D. Duarte, seu irmão, sugerindo

"que na dita Universidade houvesse dois ou mais Colégios", que "ordenassem êstes Colégios por maneira de Oxford e de Paris", e justificava a sua sugestão, pois "assim cresceriam os Letrados, e as Ciências, e os senhores achariam donde tomassem $\mathrm{Ca}$ pelões honestos e atendidos, e quando tais promovessem não seriam desditos, e até disto se seguiria que vós achareis Letrados para Oficiais da Justiça, e quando alguns vos desprouvessem, terieis donde tomar outros, e eles temendo-se do que poderia acontecer, serviriam melhor e com mais diligência" (15).

Não se realizou o desejo do infante D. Pedro. E outras tentativas de idêntico sentido, isto é, objetivando o estabelecimento de colégios, malograram. Como também malogrou a iniciativa do mesmo infante D. Pedro que pretendeu criar uma nova Universidade em Coimbra. Não é de estranhar assim que no século XV - não tanto porque a Universidade estivesse decadente, como acreditam os autores portu-

(14) . - Saraiva, op . cit., v. I, p. 445 .

(15). - Apud Brandão e Lopes de Almeida, op : cit., p. 138-9. 
guêses pois, para decair precisaria ela ter anteriormente se alevantado, e isto não aconteceu, e sim, muito mais devido à sua congênita fraqueza cultural - se reativasse de maneira até então, nunca vista, a corrente migratória de estudantes portuguêses que iam para o estrangeiro

"a pedir às Universidades, que lá floresciam; a cultura literária e científica que a nossa, segundo parece, não dava em medida suficiente" (16):

sabemos que em 1432 estudantes portuguêses formavam uma das dezesseis nações ultramontanas da Universidade de Bolonha; em 1440 a Universidade se queixava em Côrtes de que alguns estudantes, depois de estudarem em Lisboa, vão tomar grau no estrangeiro (17), o que levou Saraiva a acreditar

"que os graus de certas universidades estrangeiras eram mais acatados, e, portanto, davam maiores vantagens que os de Lisboa" (18).

entre 1470-1495 havia uns $30 \mathrm{em}$ Siena e

"é importante constatar que até 1480 os portuguêses formavam o grupo estrangeiro de longe o mais numeroso nessa Universidade" (19).

Enfim, nos inícios das grandes descobertas, no limiar da Idade Moderna, não possuia Portugal

$$
\begin{aligned}
& \text { to" "uma escola digna das aspirações culturais do Renascimen- } \\
& \text { (20). }
\end{aligned}
$$

Dessa forma a Universidade pouco contribuiu, ou melhor, nada contribuiu para a integração de Portugal no quadro da cultura européia.

Além da sua pobreza, revelava a cultura portuguêsa, na passagem para a Idade Moderna, impressionante anacronismo, demons-

(16). - Vasconcelos, op. cit., v. I, p. 116.

(17). - Livro Verde, p. 205.

(18). - Op. cit., v. I, p. 109.

(19). - Luis de Matos, Les Portugais en France au XVIe siècle, p. 144.

(20). - Brandão e Lopes de Almeida, op. cit.; p.! 149. 
trando claramente que ela não conseguia evoluir, no mesmo compasso de evolução da cultura européia. A cultura clerical, anacrônicamente, ainda encontrava no mosteiro de Alcobaça o seu grande foco; consistia ela

\begin{abstract}
"sobretudo na Patrística, em grande parte assimilada através de compêndios como as Colaç̧ões de João Cassiano, os quatro livros das Sentenças de Pedro Lombardo, as Regras, e outras obras de edificação conventual e mística (especialmente as de Hugo de São Victor e São Bernardo) ou de preceptiva sacramental e littúrgica, além, é claro, da propedêutica contida no essencial das Artes Liberais"; a "bibliografia de quatro monges agostinhos que professavam na Universidade portuguêsa durante os séculos XIV e XV - Fr. Afonso de Portugal, Fr. Agostinho Belo, Fr. Rodrigo da Cruz e Fr. João da Madalena - quase se limita a comentários sobre o Mestre das Sentenças": mas este "era o nivel atingido pela Universidade parisiense já no século XII" (21);
\end{abstract}

o tomismo, muito embora a escolástica, no restante da Europa estivesse numa fase de decadência final, era a corrente filosófica predominante; do ockhamismo não encontramos vestígios; e o mesmo se pode dizer quanto às teses de Marsílio de Pádua, a respeito da superioridade dos concílios sôbre o papa. A cultura laica, por outro lado, também não era menos pobre e anacrônica do que a clerical: na côrte de $D$. Fernando ainda não se conheciam as regras elementares da cavalaria; e dos romances da Távola Redonda, apesar de começarem a ser lidos na côrte, nos fins do século XIII, apenas

"é no século XV que encontramos testemunhos da sua grande difusão" (22);

o conceito de monarquia de D. Duarte, no Leal Conselheiro, era ainda o, do feudalismo,

"pois ele não distingue entre os reis e os outros senhores, atribuindo a uns e outros as mesmas obrigações" (23),

(21). - Saraiva, op. cit., v. I, p. 676-7.

(22). - Saraiva, op. cit., v. I, p. 544.

(23). - Saraiva, op. cit., v. I, p. 624. 
e arcáicas eram também as suas concepções, a respeito da sociedade, já que ao dividi-la em cinco "estados", não faz sequer alusão aos mercadores, classe tão importante no seu tempo; predominava a mentalidade cavaleiresca, precisamente, na época em que se iniciava a expansão ultramarina; e não deixa de ser sintomático o comportamento do monarca português, diante do apêlo de Cruzada, lançado pelo papa em 1453, impressionado com a ameaça de invasão da Europa pelos turoos:

"Como notou um historiador português — refere-se a Veiga Simões - a Cruzada, empresa tipicamente senhorial, era um anacronismo na época do fortalecimento do poder real e da formação dos grandes estados centralizados. Ao contrário, porém, dos outros príncipes, o rei português tomou a sério o apelo pontifício e preparou uma expedição. Em 1456, tomada Constantinopla pelos turcos e renovada. a exortação, D. Afonso $\mathrm{V}$ preparou-se para partir. O seu Conselho, porém, considerando a indiferença dos restantes príncipes da Cristandade interveio para o dissuadir" (24).

Partia assim Portugal para a descoberta geográfica do Mundo, sem antes ter completadò a descoberta cultural da Europa, procurando compensar as desvantagens da sua "mais longínqua gravitação no sistema da Europa culta, pelas vantagens de uma atração mais decisiva, exercida pelas ilhas misteriosas e pelas riquezas da costa africana" (25). Não é nosso propósito discutir aqui - até porque ultrapassaria de muito o âmbito cronológico das nossas preocupações se houve realmente compensação. Sabemos, no entanto, que, na Idade Média, a cultura portuguêsa nunca conseguiu compensar o seu anacronismo com relação à cultura européia, sempre se ressentindo dêle e que, a nenhum povo fazia tanta falta o ar da Europa como ao povo português.

\section{BIBLIOGRAFIA.}

ADAMSON (J. W.), Enseñanza, in "El Legado de la Edad Media", Madrí, Ediciones Pegaso, 1950.

AFONSO, O SÁBIO, Las Siete Partidas, Madrí, Imprenta Real, 1807, 3 vs. ALMEIDA (Fortunato de), História da Igreja em Portugal, Coimbra, Editor-Fortunato de Almeida, 1910-24, 8 vs.

(24). - Saraiva, op. cit., v. I, p. 591.

(25). - H. Cidade, op. cit., v. I, p. 86. 
ALMEIDA (Fortunato de), História de Portugal, Coimbra, Editor-Fortunato de Almeida; 1922-29, 6 vs.

ALPHANDERY (Paul), La Chrétienté et l'Idée de Croisade, Paris, Editions Albin Michel, 1959, 2 vs.

AZEVEDO (J. Lúcio de), A circulação das riquezas, in "História de Portugal", Barcelos, Portucalense Editôra, direção de Peres-Cerdeira, 1931, v. II.

AZEVEDO (J. Lúcio de), Complemento da vida econômica, in "História de Portugal", Barcelos, Portucalense Editôra, direção de Peres-Cerdeira, 1931, v. II.

AZEVEDo (J. Lúcio de), Epocas de Portugal Econômico, Lisboa, Livraria Clássica Editôra, 1929.

AZEVEDo (J. Lúcio de), O período agrário, in "História de Portugal", Barcelos, Portucaleṇse Editôra, direção de Peres-Cerdeira, 1931, v. II.

AZEVEDO (J. Lúcio de), O período construtivo, in "História de Portugal", Barcelos, Portucalense Editôra, direção de Peres-Cerdeira, 1931, v. II.

AZEVEDO (J. Lúcio de), Portugal potência mercantil, in "HistNria de Portugal", Barcelos, Portucalense Editôra direção de Peres-Cerdeira, 1931, v. III.

BARROS (Henrique da Gama), História da Administração Pública em Portugal, Lisboa, Livraria Sá da Costà-Editôra, 1945, 2a. ed., 10 vs.

BELL (Aubrey F. G.), A Literatura Portuguesa (História e Crítica), Coimbra, Imprensa da Universidade, 1931.

BLOCH (Marc), La Société Féodale. La formation des liens de dépendance, Paris, Editions Albin Michel, 1939.

BRAGA (Teófilo), História da Universidade de Coimbra nas suas relações com a Instrução Pública Portuguêsa, Lisboa, Por Ordem e na Tipografia da Academia Real das Ciências, 1892, 4 vs.

3RANDÃO (Fr. Antônio), Crônicas de D. Sancho III e D. Afonso III, Pôrto, Livraria Civilização-Editôra, 1946.

BRANDÃo (Mário) e ALMEIDA (Lopes de), A Universidade de Coimbra Esbốco da sua História, Coimbra, Por Ordem da Universidade, 1937.

BREHIER (Émile), Histoire de la Philosophie, Paris, Presses Universitaires de France, 1947, 2 ts., 7 fasc.

BRÉHIER (Émile), La Philosophic au Moyen Âge, Paris, Editions Albin Michel, 1949.

BRÉMONT, GAUDEMET e outros, L'Empire Chrétien et ses destinées en Occident du XIe au XIIIe siècle, Paris, Librairie Générale de Droit et Jurisprudence, 1944 .

BÜHLER (Johannes), Vida y Cultura en la Edad Media, México, Fondo de Cultura Económica, 1946.

CALMETTE (Joseph), L'Elaboration du Monde Moderne, Paris, Presses Universitaires de France, 1949, 3a. ed. 
CALMETTE (Joseph), La Société féodale, Paris, Librairie Armand Colin, 1.947. CARVALHO (Joaquim de), Cultura Filosófica e Científica, in "História de Portugal", Barcelos, Portucalense Editôra, direção de Peres-Cerdeira, 1931, v. IV.

CARVALHO (Joaquim de), Estudos sobre a Cultura Portuguesa no século XVI, Coimbra, Por Ordem da Universidade, 1947.

CARVALHO (Joaquim de), Instituições de Cultura, in "História da Literatura Portuguêsa Ilustrada", Lisboa, Aillaud \& Bertrand, direção de Albino Forjaz de Sampaio, 1929, v. I.

CARVAlHo (Joaquim de), Instituições de Cultura, in "História de Portugal", Barcelos, Portucalense Editôra, direção de Peres-Cerdeira, 1931, v. II.

CIDADE (Hernani), Conceito de Poesịa como Expressão da Cultura, Coimbra, Américo Amado-Editor, 1945.

CIDADE (Hernani), Lições de Cultura e Literatura Portuguêsa, Coimbra, Coimbra Editôra Ltda., 1951, 3a. ed., 2 vs.

CORREIA (Alexandre), A Universidade Medieval, in "Revista da Faculdade de Direito", São Paulo, 1950, v. XLV.

CORREIA (Antônio), História Econômica de Portugal, Lisboa, Emprêsa Nacional de Publicidade, 1929-31, 2 vs.

CORREIA (Vergílio), A escultura em Portugal - $O$ século $X I I-O$ século $X I I I$, in "Biblos", Coimbra, 1929, v. V, n's 9 e 10.

CORTESÃO (Jaime), $O$ desígnio do Infante e as explorações atlânticas até à sua morte, in "História de Portugal", Barcelos, Portucalense Editôra direção de Peres-Cerdeira, 1931, v. III.

CORTESÃO (Jaime), Os fatores democráticos na formação de Portugal, in "História do Regime Republicano em Portugal", Lisboa, Publicada por Luís de Montalvor, 1930, v. I.

COSTA (Antônio da), História da Instrução Pública em Portugal desde a Fundação da Monarquia até aos nossos dias, Pôrto, Editor-Antônio Figueirinhas, 1900, 2a. ed.

COSTA (João Cruz), O Desenvolvimento da Filosofia no Brasil. no século XIX e a evolução listórica nacional, São Paulo, 1950.

DAVID (Pierre), Lees Français du Midi dans les évêchés portugais (1279-1382), in "Bulletin des Études Portugaises au Portugal", Coimbra, Coimbra Editôra, Ltda, 1943, fasc. 2.

DEANESLY (Margaret), A History of the Medieval Church. 590-1500, Londres, Methuen \& Co. Ltda., 1951, 7a. ed.

DEANESLY (Margaret), Medieval Schools to c. 1.300, in "Cambridge Medieval History", Cambridge, The University Press, 1929, v. V.

DECARREAUX (J.); Les Moines et la Civilisation en Occident. Des envasions à Charlemagne, Paris, Arthaud, 1962.

DENIFLE (H.), A Universidade de Lisboa-Coimbra.. Capítulo de uma obra alemã, Coimbra, Imprensa da Universidade, 1892. 
DIEHL (C.) e MARÇAIS (G.), Le Monde Oriental de 395 à 1.081, Paris, Presses Universitaires de France, 1936.

DILTHEY (Wilhelm), Historia de la Pedagogia, Buenos Aires, Editorial Losada, S. A., 1957.

ELBY (F.) e ARROWOOD (C.), The History of Philosophy of Education Ancient and Medieval, Nova York, Prentice-Hall, Inc., 1953.

FERREIRA (Francisco Leitão), Noticias Chronológicas da Universidade de Coimbra, Coimbra, Por Ordem da Universidade de Coimbra, 1937, 2a. ed., 1a. parte.

FLICHE (Augustin), La Chrétienté Médiévale (395-1254), Paris, E. de Boccard, Editeur, 1929.

FLICHE (A.), FOREVILLE (R.), ROUSSET (J.), Du premier Concile du Latran à l'avènement d'Innocent III (1123-1198), in "Histoire de l'Eglise depuis les origines jusqu'à nos jours", direção de Fliche e Jarry, Paris, Bloud \& Gay, 1948, v. IX.

FRANÇA (E. d'Oliveira), O Poder Real em Portugal e as Origens do Absolutismo, São Paulo, Boletim LXVIII da Faculdade de Filosofia, Ciências e Letras da Universidade de São Paulo, 1946.

FRANK (Istvan), Les Troubadours et le Portugal, in "Mélanges d'Études Portugaises offerts à M. Georges Le Gentil", Lisboa, Instituto para a Alta Cultura, 1949.

GENICOT (Leopold), Les Lignes de Faîte du Moyen Âge, Tournai-Paris, Editions Castenau, 1951.

GILSON (Etienne), La Filosofia en la Edad Media - Desde los orígenes patrísticos hasta el fin del siglo XIV, Madrí, Biblioteca Hispanica de Filosofia, 1958, 2 vs.

GOOD (H. G.), A History of Western Education; Nova York, The Macmillan Company, 1960.

HALPHEN (Louis), Les Barbares - Des grandes invasions aux conquêtes turques de XIe siècle, Paris, Presses Universitaires de France, 1940, $4 a$. ed.

HALPHEN (Louis), Charlemagne et l'Empire Carolingien, Paris, Editions Albin Michel, 1949.

HALPHEN (Louis), L'enseignement aux XIIe et XIIIe siècles, in "Ã Travers l'Histoire du Moyen Âge", Paris, Presses Universitaires de France, 1950 .

HALPHEN (Louis), L'Essor de l'Europe (XIe-XIIIe siècles), Paris, Presses Universitaires de France, 1948, 3a. ed.

HALPHEN (Louis), L'Université au XIIIe siècle, in “À Travers l'Histoire du Moyen Âge", Paris, Presses Universitaires de France, 1950.

HASKINS (C. H.), The Rise of Universities, Nova York, Great Seal Books, 1957. 
HAZELTINE (H.), Roman and Canon Law in the Middle Ages, in "Cambridge Medieval History", Cambridge, The University Press, 1929, v. V.

HAUSER (Arnold), Storia sociale dell'arte, Giulio Einaudi Editore, 1955, 4 vs.

HEATON (Herbert), Histoire économique de l'Europe. Des origines à 1750. Paris, Librairie Armand Colin, 1950, 2 vs.

HERCULANO (Alexandre), História de Portugal, Lisboa, Livraria Allaud \& Bertrand, 8a. ed. (definitiva), 8 vs.

HOLANDA (Sérgio Buarque de), Raízes do Brasil, Rio de Janeiro, Livraria José Olímpio Editôra, 1948, 2a. ed.

IRSAY (Stephen d'), Histoire des Universités Françaises et Étrangères des o:tgines à nos jours, Paris, Editions Auguste Picard, 1933, 2 vs.

LACERDA (Aarão de), Arte, in "História de Portugal", Barcelos, Portucalense Editora, direção de Peres-Cerdeira, 1931, v. II.

LACERDA (Aarão de), Para a história das artes plásticas em Portugal durante os séculos XII, XIII e XIV, in "Congresso do Mundo Português, Lisboa, 1940, v. II.

LAGARDE (George de), La Naissance de l'esprit laïque au déçlin du Moyen Age, Paris, Presses Universitaires de France, 1942-48, 6 vs.

L.AMBERT (E.), L'église du monastère dominicain de Batalha et l'architecture cistercienne, in "Mélanges d'Êtudes Portugaises offerts à $M$. Georges Le Gentil", Lisboa, Instituto para a Alta Cultura, 1949.

LAPA (Rodrigues), Das Origens da poesia lírica em Portugal na Idade Média, Lisboa, Edição do Autor, 1929.

LAPA (Rodrigues), Lições de Literatura Portuguêsa. Epoca Medieval, Coimbra, Coimbra Editôra Limitada, 1952. 3a. ed.

LETHABY (W. R.), Arquitectura Medieval, in "El Legado de la Edad Media", Madrí,.Ediciones Pegaso, 1950.

LIVRO VERDE da Universidade de Coimbra (Cartulário do século XV), Coimbra, Publicações do Arquivo e Museu de Arte da Universidade de Coimbra, Leitura, Revisão e Prefácio de Antônio Gomes e Rocha Madahil, 1940.

LOBO (Costa), História da Sociedade em Portugal no século XV, Lisboa, Imprensa Nacional, 1907.

LOMBARD (Maurice), A evolução urbana durante a Alta Idade Média, in "Revista de Histórià", São Paulo, 1955, n' 23.

LOMBARD (Maurice), $A$ rota do Mosa e as relações longínquas das regióes mosanas entre os séculos VIII.e $X I$, in "Revista de Histó:ia, São Paulo, 1965, $\mathrm{n}^{\circ} 63$.

LOT (Ferdinand), La Fin du Monde Antique et le début du Moyen Âge, Paris, Editions Albin Michel, 1951.

LOWE (E. A.), Escritura, in "El Legado de la Edad Media", Madrí, Ediciones Pegaso, 1950. 
MATOS (Luís de), Les Portugais en France au XVIe siècle, Coimbra, Por Ordem da Universidade, 1952.

MARROU (H.-Irénée), Histoire de l'Éducation dans l'Antiquité, Paris, Editions du Seuil, 1950, 2a. ed.

MARTIN (Alfred von), Sociologia de la Cultura Medieval, Madrí, Instituto de Estudios Políticos, 1954.

MARTINS (Oliveira), Os filhos de D. João I, Lisboa, Edições S. I. T., 1947, 7a. ed.

MARTINS (Oliveira), História de Portugal, Lisboa, Parceria Antônio Maria Pereira, 1942, 12a. ed., 2 vs.

MEREA (Manuel Paulo), As fontes do direito e a justiça, in "História de Portugal", Barcelos, Portucalense Editôra, direção de Peres-Cerdeira, 1931, v. II.

MEYNIAL (Eduardo), Derecho Romano, in "El Legado de la Edad Media", Madrí, Ediciones Pegaso, 1950.

MICHÄELIS (Carolina), Cancioneiro da Ajuda, Halle, Max Niemeyer, 1904, 2 vs.

MIELI (Aldo) ,Panorama General de la Historia de la Ciencia. El Mundo Islámico y el Occidente Medieval Cristiano, Buenos Aires, Espasa-Calpe Argentina, 1952, 2a. ed.

MONTALEMBERT; Précis d'Histoire Monastique: des origines à fin du XIe siècle, Paris, Librairie Philosophique J. Vrin, 1934.

MUNDI (J. H.) e RIESENBERG (P.), The Medieval Town, Princeton, D. Van Nostrand Company, Inc., 1958.

NEWMAN (Cardeal John H.), Origem e Progresso das Universidades, São Paulo, 1951 .

NORDSTRÖM (J.), Moyen Áge et Renaissance, Paris, Librairie Stock, 1933.

NUNES (J. Joaquim), Cantigas d'Amigo, Coimbra, Imprensa da Universidade, 1928,3 vs.

NUNES (J. Joaquim), Poesia galego-portuguesa ou trovadoresca (séculos XIII a. $X V$ ), in "História da Literatura Portuguêsa Ilustrada", Lisboa, Aillaud \& Bertrand, direção de Albino Forjaz de Sampaio, 1929, v. I.

PAETOW (L. J.), A guide to the study of medieval history, Nova York, Mediaeval Academy of America, 1931.

PARÉ (G.), BRUNET (A.), TREMBLAY (P.), La Renaissance du XIIe siècle. Les écoles et l'enseignement, Otawa, Publications de l'Institut d'Etudes Médiévales d'Otawa, 1933.

PASSANT (E. J.), The Effects of the Crusades upon Western Europe, in "Cambridge Medieval History", Cambridge, The University Press, 1929, v. V.

PAUlA (E. Simões de), O comércio varegue e o Grão-Principado de Kiev, São Paulo, 1942.

PAULA (E. Simões de), As Universidades Medievais, in "Revista de História", São Paulo, 1957, n 31 . 
PERES (Damião), A Atividade agrícola em Portugal nos séculos. XII a XIV, in "Congresso do Mundo Português", Lisboa, 1940, v. II.

PETIT-DUTAILLIS (C.), Les Communes Françaises. Caractères et évolution des origines au XVIIIe siècle, Paris, Albin Michel, 1947.

PIMPÃO (A. J. da Costa), História da Literatura Portuguêsa (séculos XII a $X V)$, Coimbra, Edições Quadrante Ltda., 1947, v. I.

PINA (Rui de), Crônica de D. Denis, Pôrto, Livraria Civilização-Editôra, 1945.

PIRENNE, COHEN, FOCILLON, La Civilisation Occidentales au Moyen Âge du XIe au milieu du XVe siècle, Paris Presses Universitaires de France, 1933.

PIRENNE, RENAUDET, PERROY e outros, La fin du Moyen Áge - La désagregation du monde médiéval (1285-1453), Paris, Librairie Félix Alcan, 1931.

PIRENNE (Henri), Historia económica y social de la Edad Media, México, Fondo de Cultura Económica, 1947, 4a. ed.

PIRENNE (Henri), Histoire de l'Europe des invasions au XVIe siècle, Bruxelas, Nouvelle Société d'Editions, 1936, 6a. ed.

PIRENNE (Henri), Mahomet et Charlemagne, Bruxelas, Nouvelle Société d'Éditions, 1937, 2a. ed.

PIRENNE (Henri), Les Villes et les Institutions urbaines, Bruxelas, Nouvelle Société d'Éditions, 1939, 2 vs.

Pó (Guido), La Marina Italiana in Portogallo, in "Congresso do Mundo Português", Lisboa, 1940, v. III.

POOLE (A. L.), Frederick Barbarossa and Germany, in "Cambridge Medieval History, Cambridge, The University Press, 1929, v. V.

PORTUGALIAE MONUMENTA HISTORICA a saeculo octavo post Christum usque ad quintumdecimum, iussu Academiae Scientiarum Olisiponesis edita. Typis Academiae. Olissipone.

PREVITÉ-ORTON (C. W.), The Shorter Cambridge Medieval History, Cambridge, The University Press, 1953, 2 vs.

RASHDALL (Hastings), The Medieval Universities, in "Cambridge Medieval History", Cambridge, The University Press, 1936, v. VI.

RASHDALL (Hastings), The Universities of Europe in "the Middle Ages", Oxford University Press, 1936, 2a. ed. 3 vs.

RAU (Virgínia), Subsidios para o Estudo das Feiras Medievais Portuguêsas, Lisboa, 1943.

READE (W. H. V.), Philosophy in the Middle Ages, in "Cambridge Medieval History", Cambridge, The University Press, 1929, v. .

REGO (J. Teixeira), A Literatura, in "História de Portugal", Barcelos, Portucalense Editôra, direçăo de Peres-Cerdeira, 1931, v. II.

RIBEIRO (Ângelo), Oltimas conquistas e definição territorial, in. "História de Portugal", Barcelos, Portucalense Editôra, direção de Peres-Cerdeira, 1931, v. II. 
RIBEIRO (Ângelo), Politica de fomento nacional, in "História de Portugal", Barcelos, Portucalense Editôra, direção de Peres-Cerdeira, 1931, v. II.

RIBEIRO (José Silvestre), História dos Estabelecimentos Científicos, Literários e Artísticos de Portugal nos Sucessivos Reinados da Monarquia, Lisboa, Tipografia da Academia Real das Ciências, 1871-93, 18 vs.

RIVAUD (Albert), Histoire de la Philosophie, Paris, Presses Universitaires de France, 1950, 2 vs.

SAITTA (Giuseppe), Arti Liberali, in "Enciclopedia Italiana di Scienze, Lettere ed Arti", Roma, Istituto Giovanni Treccani, v. IV.

SANDYS (J. E.), A History of Classical Scholarship, Cambridge, The University Press, 1921, 3a. ed., 3 vs.

SANTOS (Fr. Manuel dos), Alcobaça llustrada, Coimbra, 1710.

SANTOS (Reinaldo dos), A Arte Medieval, in "História da Literatura Portuguêsa Ilustrada", Lisboa, Aillaud \& Bertrand, direção de Albino Forjaz de Sampaio, 1929, v. I.

SARAIVA (Antônio José), História da Cultura em Portugal, Lisboa, Jornal do Fôro, 1950-62, 3 vs.

SAVIGNY (F. C.), Histoire du Droit Romain au Moyen Âge, Paris, Alexandre Mosnier, 1830, 2 vs.

SÉRGIO (Antônio), Em tôrno da designação de Monarquia Agrária dada à primeira época da nossa história, Lisboa, Livraria Portugália, 1941.

SERGIO (Antônio), História de Portugal, Barcelona, Editorial Labor, 1929.

SCHAEFER (H.), História de Portugal, Pôrto, Escritório da Emprêsa Editôra, $1893-99,5$ vs.

SCHNƯRER (Gustave), L'Église et la Civilisation au Moyen Âge, Paris, Payot, 1933-5, 3 vs:

SOARES (Torquiato de Sousa), Linha de rumo da História de Portugal, São Paulo, 1958 .

SPINA (Segismundo), Apresentação da Lírica Trovadoresca, Rio de Janeiro, Livraria Acadêmica, 1956.

THOMAS (Lothar), Contribuição para a História da Filosofia Portuguêsa, Lisboa, Livraria Clássica Editôra, 1944.

THUT (I.,N.), The Story of Education (Philosophical and Historical Foundations), Nova York, McGraw - Hill Book Company, Inc., 1957.

TOFFANIN (Giuseppe), Il Secolo senza Roma (Il Rinascimento del secolo $X I I I)$, Bolonha, Nicola Zanichelli Editore, 1943.

VASCONCELOS (Antônio), Um documento precioso: o diploma dionisiano de fundação da Universidade portuguesa, in "Escritos Vários Relativos à Universidade Dionisiana", Coimbra, Coimbra Editôra Ltda., 1938, v. I.

VEIGA (Mota), Esbộço Histórico-Literário da Faculdade de Teologia da Universidade de Coimbra, Coimbra, Imprensa da Universidade, 1872. 
VERLINDEN (Charles), Le problème de l'expansion commerciale portugaise au Moyen Âge, in "Biblos", Coimbra, Coimbra Editôra Ltda., 1947, v. XXIII, t. II.

VIGNAUX (Paul, La Pensée au Moyen Áge, Paris, Librairie Armand Colin, 1948, 2a. ed.

VINOGRADOFF (Paul), Diritto Romano nell'Europa Medioevale, Milão, Dott. A. Giuffrè-Editore, 1950.

VITERBO (Fr. Joaquim de Santa Rosa), Elucidário das Palavras e Frases que em Portugal antigamente se usaram e que hoje regularmente se ignoram, Lisboa, A. J. Fernandes Lopes, 1865.

WEBER (Alfred), Historia de la Cultura, México, Fondo de Cultura Económica, 1948, 2a. ed.

WEBER (Max), La Città, Milão, Valentino Bompiani, 1950.

WULF (Maurice De), Histoire de la philosophie médiévale, Louvain, Institut Supérieur de Philosophie, 1934, 2 vs. 